\title{
RANCANG BANGUN SISTEM INFORMASI AKUNTANSI PADA CV. MANIK GALIH BERBASIS WEBSITE
}

\author{
${ }^{1}$ Ni Putu Dita Ariani Sukma Dewi, ${ }^{2}$ I Made Dwi Putra Asana, ${ }^{3}$ I Putu Susila Handika \\ ${ }_{1,2,3}$ Program Studi Teknik Informatika, STMIK STIKOM Indonesia \\ Email: 1ditaariani.da@gmail.com
}

DOI: https://doi.org/10.46880/jmika.Vol4No1.pp15-21

\begin{abstract}
ABSTRAK
CV. Manik Galih merupakan sebuah perusahaan dagang yang bergerak di bidang industri mebel serta alat-alat elektrikal. Perusahaan ini didirikan pada tanggal 11 Februari 2014 oleh Komang Sri Ari Lestari. CV. Manik Galih berlokasi di Jl. Muding Indah Gg. Ratnasari No 10, Kelurahan Kerobokan Kaja, Kecamatan Kuta Utara, Kabupaten Badung. Permasalahan yang dihadapi pada CV. Manik Galih yaitu saat melakukan pencatatan transaksi keuangan, transaksi tersebut dibuat dalam sheet yang tidak beraturan, ketidakberaturan yang dimaksud adalah tidak sesuainya penempatan antara transaksi pada jurnal harian dengan akun-akun yang dibuat dalam buku besar yang mempengaruhi keakuratan data transaksi, sehingga pembuatan laporan neraca menjadi tidak seimbang (balance). Metode yang digunakan untuk membuat sistem informasi akuntansi pada CV. Manik Galih adalah metode wawancara, dokumentasi dan studi pustaka. Manfaat dan tujuan dari penelitian ini adalah membantu dalam mengelola data penjualan, pembelian serta menghasilkan laporan keuangan yang akurat dan tidak membutuhkan waktu yang lama. Hasil dari penelitian ini adalah menghasilkan sebuah program sistem informasi akuntansi berbasis website yang diharapkan dapat menjawab permasalahan yang dihadapai oleh CV. Manik Galih. Hasil pengujian dengan blackbox testing sistem informasi akuntansi pada CV. Manik Galih dinyatakan telah sesuai dengan fungsinya.
\end{abstract}

Kata Kunci: Sistem Informasi Akuntansi, Berbasis Website, Blackbox Testing

\section{PENDAHULUAN}

Setiap perusahaan dalam mengukur kinerja keuangan membutuhkan akses informasi keuangan yang mudah. Informasi keuangan dalam bentuk laporan keuangan menjadi dasar bagi pemangku kebijakan perusahaan dalam pengambilan keputusan. Pada laporan keuangan menggambarkan kondisi keuangan perusahaan dari sisi aset, hutang, modal, dan pendapatan. Mengakses laporan keuangan dengan mudah dan akurat menjadi tantangan bagi perusahaan yang tidak memiliki sistem pengelolaan data keuangan yang baik. Salah satu usaha yang dapat dilakukan untuk meningkatkan kualitas pengelolaan data keuangan adalah penerapan sistem informasi akunting berbasis komputer.

CV. Manik Galih adalah perusahaan yang bergerak di bidang usaha meubel serta alat-alat elektrikal. Perusahaan ini didirikan pada tanggal 11 Februari 2014 oleh Komang Sri Ari Lestari. CV. Manik Galih berlokasi di Jl. Muding Indah Gg. Ratnasari No 10, Kelurahan Kerobokan Kaja, Kecamatan Kuta Utara, Kabupaten Badung. CV. Manik Galih memiliki 5 tenaga kerja administratif yang memiliki tugas utama menyusun transaksitransaksi yang terjadi di perusahaan meliputi transaksi penjualan, pembelian, dan menyusun pelaporan keuangan, serta memiliki 5 tenaga kerja produksi yang bertugas untuk membuat mebel sesuai dengan pesanan yang telah ditentukan. Dalam sebulan, CV. Manik Galih dapat menangani 3 sampai 4 kontrak kerja yang setiap kontraknya berisi 10 sampai 15 pesanan mebel dan alat elektrikal. Pada akhir periode, setiap bulannya CV. Manik Galih akan membuat laporan keuangan untuk menggambarkan keadaan keuangan perusahaan.

Berdasarkan hasil wawancara dengan Komang Sri Ari Lestari selaku pemilik CV. Manik Galih, sistem yang berjalan saat ini pada CV. Manik Galih sudah terkomputerisasi dengan menggunakan Microsoft Excel dimana terdapat beberapa tahap kegiatan yang dilakukan, mulai dari pencatatan penjualan, pembelian, hutang piutang, serta pencatatan dari nota transaksi lainnya yang menyangkut keuangan. Setelah masing-masing transaksi telah selesai dicatat, tahap selanjutnya yakni membuat laporan keuangan dari transaksi tersebut. Namun, masing-masing transaksi tersebut dibuat dalam sheet yang tidak beraturan, ketidakberaturan yang dimaksud adalah tidak sesuainya penempatan antara transaksi pada jurnal harian dengan akun-akun yang dibuat dalam buku besar yang mempengaruhi keakuratan 
data transaksi, sehingga pembuatan laporan neraca menjadi tidak seimbang (balance). Permasalahan pengelolaan data keuangan tersebut mengakibatkan penyusunan laporan keuangan terhambat. Laporan keuangan yang lambat pada akhirnya berdampak pada pengambilan keputusan dari sisi pimpinan perusahaan.

Dari permasalahan yang telah dipaparkan, untuk meningkatkan kinerja pelaporan keuangan pada $\mathrm{CV}$. Manik Galih maka dibutuhkan sistem informasi akuntansi terkomputerisasi yang mampu mengolah data penjualan, pembelian, hutang piutang menjadi sebuah laporan keuangan. Beberapa penelitian telah dilakukan mengenai pengembangan sistem informasi akuntasi pada perusahaan barang maupun jasa dari Yulianton, dkk (2014), Juniastini (2018), Megawati, dkk (2018). Pada penelitian tersebut telah berhasil dikembangkan sistem informasi akuntansi berbasis website yang dapat memudahkan pengguna dalam mengakses informasi. Dengan memanfaatkan sistem diharapkan dapat membantu pembuatan laporan keuangan dengan lebih baik. Maka dari itu, pada artikel ini dirancang dan dibangun sebuah sistem informasi yang berjudul "Rancang Bangun Sistem Informasi Akuntansi Pada CV. Manik Galih Berbasis Website".

\section{TINJAUAN PUSTAKA}

\section{Sistem Informasi}

Sistem informasi merupakan kumpulan komponen yang saling berkaitan untuk menghasilkan informasi sesuai dengan tujuan organisasi. Setiap komponen mempunyai fungsi pengumpulan, pemrosesan, penyimpanan, analisis, dan penyebaran informasi (Sutarman, 2009) \& (James A Hall, 2011).

\section{Akuntansi}

Akuntansi adalah ilmu yang menjabarkan cara pembuatan informasi keuangan suatu organisasi atau perusahaan dan cara melaporkan informasi tersebut kepada pihak yang berkepentingan untuk dijadikan dasar dalam pengambilan keputusan. (Suwardjono, 2014).

\section{Sistem Informasi Akuntansi (SIA)}

Sistem Informasi Akuntansi

merupakan proses pengumpulan dan pengolahan data serta melaporkan informasi yang berkaitan dengan transaksi keuangan. (Diana \& Lilis Setiawati, 2011). SIA terdiri beberapa modul sistem yaitu pemrosesan transaksi, penyusunan buku besar, dan pengendalian manajemen (David Efendi, 2013).
Berdasarkan beberapa fungsi dari SIA, fungsi SIA yang ditekankan pada artikel ini adalah mengoptimalkan pengendalian akuntasi melalui penyediaan laporan lengkap mengenai informasi keuangan dan pengurangan biaya tambahan dalam penyelenggaraan catatan akuntansi (Mulyadi, 2016).

Penerapan SIA berbasis komputer dapat membantu dalam proses penyusunan laporan keuangan. SIA berbasis komputer dapat menyusun laporan keuangan secara langsung berdasarkan inputan yang dilakukan oleh pengguna. Sehingga tidak dilakukan penginputan data transaksi yang sama secara berulang (Duma Megaria Elisabeth, 2019).

Teknologi komputer dalam penggunaan sistem informasi tentunya akan lebih efisien karena cepatnya pengolahan data dengan bantuan basis data, perusahaan dapat melihat data yang diolah atau informasi masa lalu milik perusahaan untuk kepentingan pemeriksaaan (audit). Anggaran perusahaan juga dapat dibuat berdasarkan informasi dari sistem informasi akuntansi yang telah diolah dan disajikan (MH Adzim, 2015).

\section{METODE PENELITIAN}

Dalam memenuhi kebutuhan perancangan SIA pada CV. Mani Galih, metode penelitian yang digunakan pada artikel ini adalah pengumpulan data primer dan sekunder.

\section{Data Primer}

Data primer (Umi Narimawati, 2010) ialah data yang berasal dari sumber asli atau pertama. Metode pengumpulan data primer yang digunakan untuk dalam proses pembuatan rancang bangun sistem informasi akuntansi pada CV. Manik Galih berbasis website antara lain :

a. Metode Wawancara

Pada metode wawancara ini, telah dilakukan tanya jawab langsung kepada Komang Sri Ari Lestari selaku pemilik CV. Manik Galih mengenai hal-hal yang terkait dengan sistem akuntansi yang ada di CV. Manik Galih.

b. Metode Observasi

Pada metode observasi ini telah dilakukan dengan cara mengamati proses pencatatan keuangan yang ada di CV. Manik Galih. Dari hasil pengamatan yang dilakukan, didapatkan data yang dibutuhkan untuk kemudian diproses pada pembuatan rancangan sistem. 


\section{Data Sekunder}

Data sekunder (Hua, 2016) didefinisikan sebagai data yang telah dikumpulkan oleh pengkaji lain. Metode pengumpulan data sekunder yang digunakan dalam proses pembuatan rancang bangun sistem informasi akuntansi pada CV. Manik Galih berbasis website antara lain:

a. Metode Kepustakaan

Pada metode kepustakaan dilakukan dengan mengumpulkan data dari berbagai sumber buku ajaran atau buku yang dipelajari selama perkuliahan maupun informasi serta menganalisa dengan kajian pustaka sebagai landasan teori.

b. Metode Dokumentasi

Pada metode dokumentasi dilakukan dengan mengambil sumber data melalui gambar.

\section{ANALISIS DAN PERANCANGAN}

Tahap analisis dilakukan untuk memahami proses bisnis yang sedang berjalan pada perusahaan. Pemahaman proses bisnis didukung dengan data primer dan teori kepustakaan tentang SIA. Hasil analisis dituangkan dalam document flow diagram (diagram alir dokumen).

\section{Analisis Sistem yang Berjalan}

Analisis yang dilakukan dalam penelitian ini berdasarkan informasi dari pimpinan mengenai alur sistem yang sedang berjalan baik penjualan, pembelian, serta keuangan yang sedang berjalan dan terdapat di CV. Manik Galih. Sebelum membangun sistem informasi akuntansi, terlebih dahulu dipaparkan penjelasan mengenai alur akuntansi maupun alur terjadinya penjualan dan pembelian alat dan bahan, serta alur pembayaran barang secara kredit.

\section{Document Flow Diagram Proses Penjualan Barang Custom}

Pada Gambar 1 dan 2 memaparkan mengenai Document Flow Diagram proses penjualan barang custom yang terjadi di CV. Manik Galih.

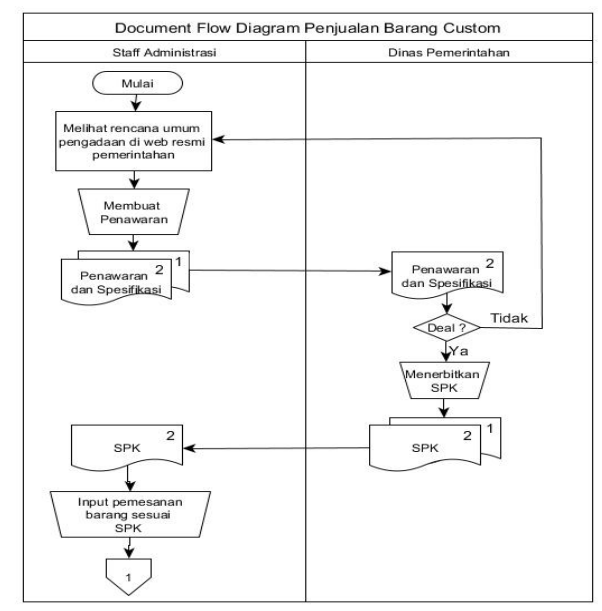

Gambar 1. Document Flow Diagram Proses Penjualan Barang Custom pada CV. Manik Galih ( I )

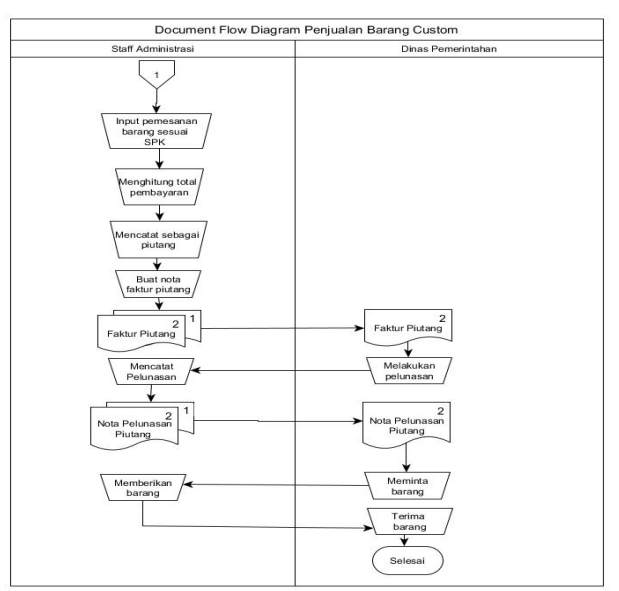

Gambar 2. Document Flow Diagram Proses Penjualan Barang Custom pada CV. Manik Galih ( II )

\section{Document Flow Diagram Proses Pembelian Alat dan Bahan}

Pada Gambar 3 dan 4 menjelaskan Document Flow Diagram proses pembelian alat dan bahan yang terjadi di CV. Manik Galih.

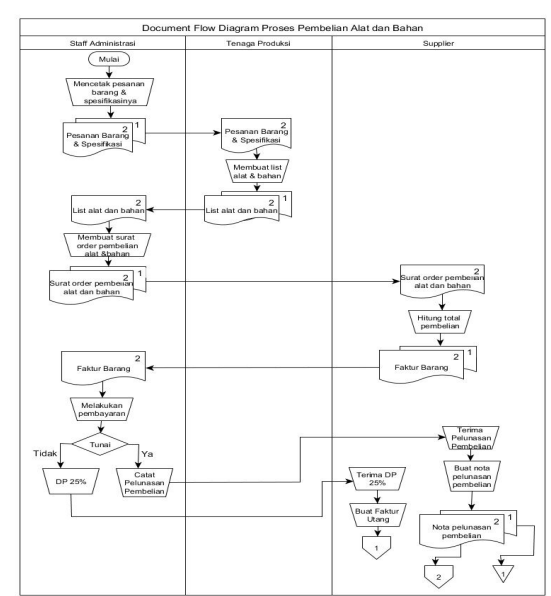

Gambar 3. Document Flow Diagram Proses

Pembelian Alat dan Bahan pada CV. Manik Galih ( I ) 


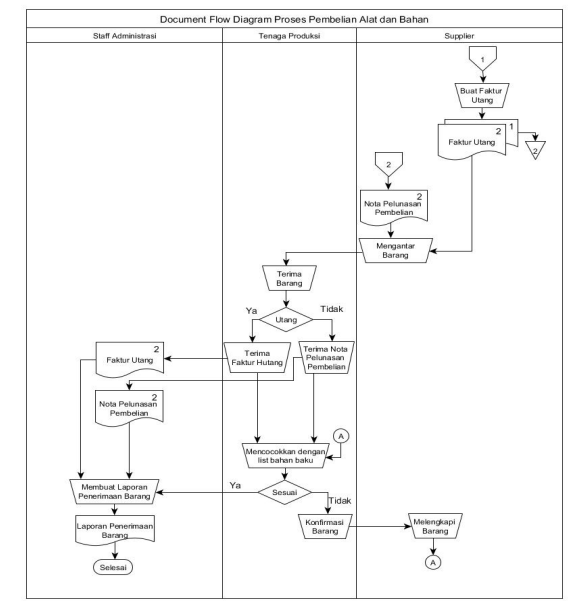

Gambar 4. Document Flow Diagram Proses

Pembelian Alat dan Bahan pada CV. Manik Galih (II)

\section{Document Flow Diagram Proses Pembayaran \\ Kredit Alat dan Bahan}

Pada Gambar 5 menjelaskan Document Flow Diagram proses pembayaran kredit alat dan bahan yang terjadi di CV. Manik Galih.

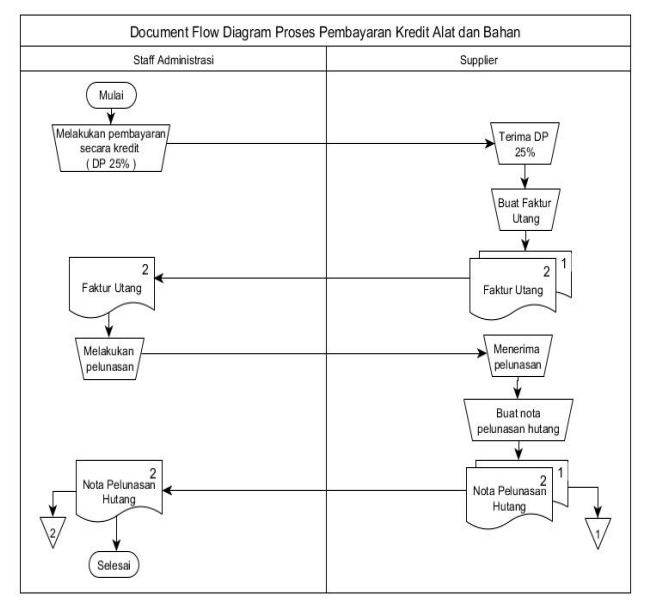

Gambar 5. Document Flow Diagram Proses Pembayaran Kredit Alat dan Bahan

\section{Document Flow Diagram Proses Akuntansi}

Pada Gambar 6 menjelaskan Document Flow Diagram proses akuntansi yang terjadi di CV. Manik Galih.

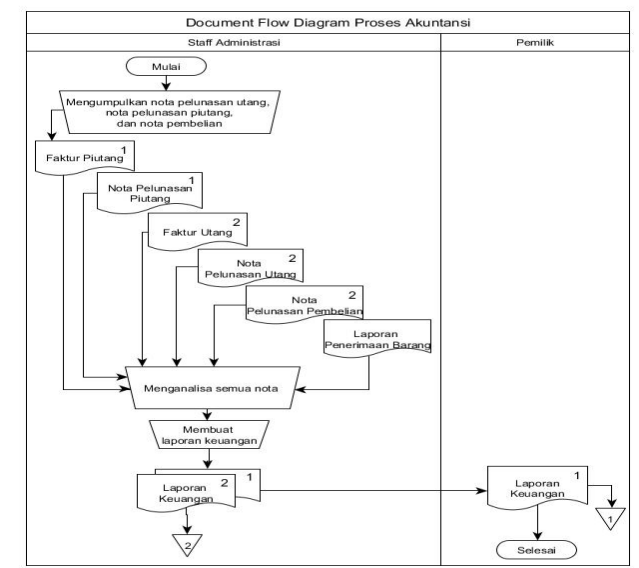

Gambar 6. Document Flow Diagram Proses Akuntansi pada CV. Manik Galih

\section{Analisis Sistem yang Diajukan}

Dari permasalahan yang ada dan berdasarkan hasil analisis sistem yang sedang berjalan, maka diajukan suatu rancangan sistem yang nantinya dapat membantu meminimalkan dan mengatasi permasalahan yang ada dengan gambaran dalam data flow diagram level 0, Conceptual Data Model, dan Physical Data Model.

\section{Data Flow Diagram Level 0}

Data Flow Diagram Level 0 merupakan diagram alir data yang menjelaskan tentang seluruh proses pengelolaan sistem dari pengguna. Alir yang berbentuk garis menjelaskan ke arah mana proses yang terjadi dalam pengiriman data. Data Flow Diagram Level 0 dari sistem informasi akuntansi pada CV. Manik Galih terdiri dari 6 proses yakni mengelola data user, mengelola data master, mengelola data transaksi pembelian alat dan bahan, mengelola data transaksi penjualan barang custom, mengelola data jurnal dan mengelola laporan.

\section{Conceptual Data Model}

Pada Gambar 7 merupakan Conceptual Data Model yang digunakan untuk menggambarkan secara detail struktur basis data dalam bentuk konsep atau logic. 


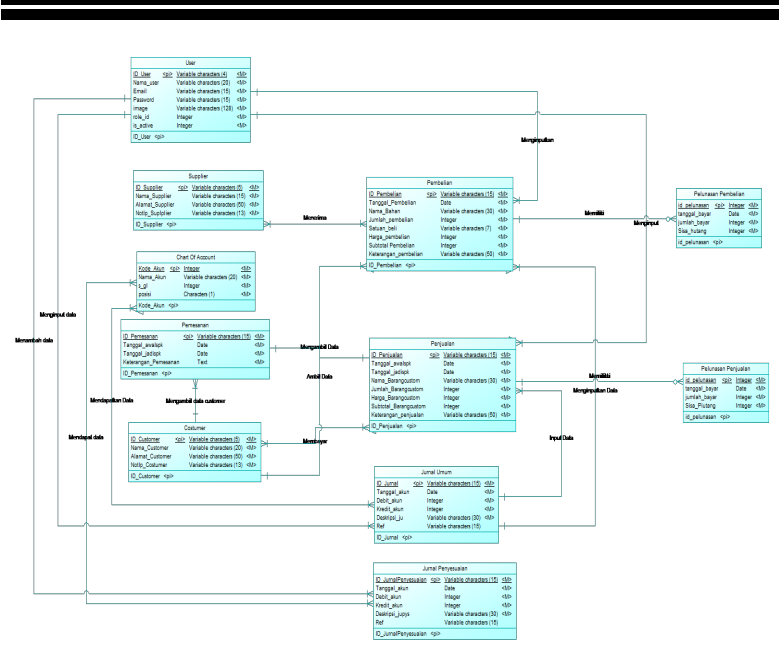

Gambar 7. Conceptual Data Model

\section{Physical Data Model}

Pada Gambar 8 merupakan Physical Data Model yang digunakan untuk menggambarkan secara detail struktur basis data dalam bentuk fisik.

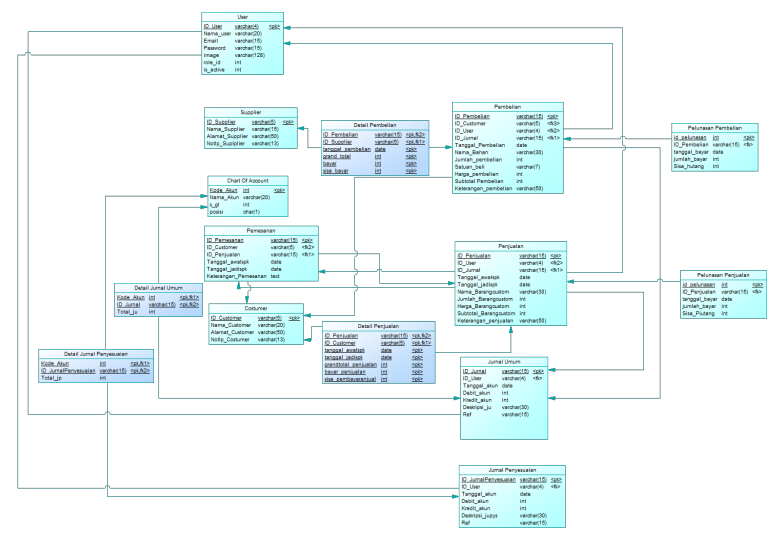

Gambar 8. Physical Data Model

\section{IMPLEMENTASI DAN PEMBAHASAN}

Implementasi sistem membahas mengenai tahapan lanjutan pelaksanaan dan penerapan dari sistem yang sudah dianalisis terlebih dahulu. Setelah dilakukan penerapan maka sistem akan diuji, apakah sistem yang dibuat dapat berjalan dengan baik atau tidak.

\section{Halaman Login}

Halaman login merupakan halaman yang digunakan untuk masuk ke halaman utama (dashboard). Terdapat dua hak akses yaitu Pemilik dan Staff Administrasi. Halaman login dapat dilihat pada Gambar 10.

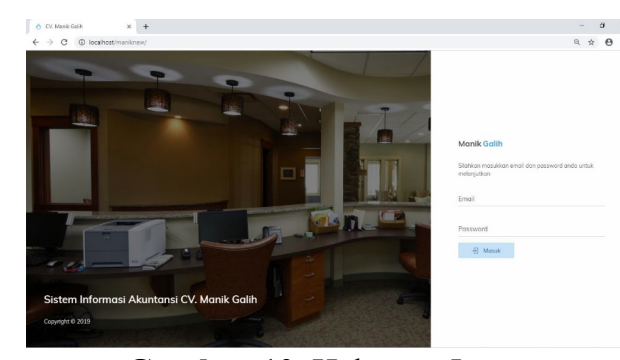

Gambar 10. Halaman Login

\section{Halaman Utama Pemilik}

Pada Gambar 11 merupakan halaman utama yang akan muncul ketika user sudah melakukan proses login. Pemilik dapat mengakses dua menu pada navigasi di sebelah kiri yakni data user dan data laporan.

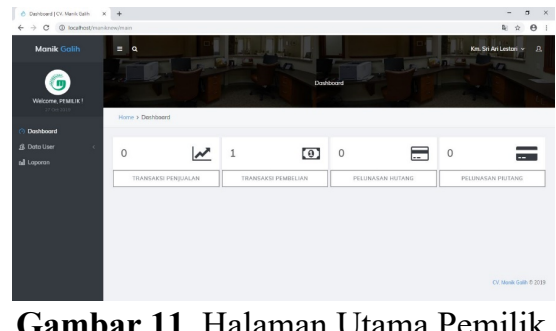

\section{Halaman Utama Staff Administrasi}

Pada Gambar 12 merupakan halaman utama yang akan muncul ketika user sudah melakukan proses login. Staff administrasi dapat mengakses beberapa menu pada navigasi di sebelah kiri diantaranya data master, data pembelian, data penjualan, dan data jurnal.

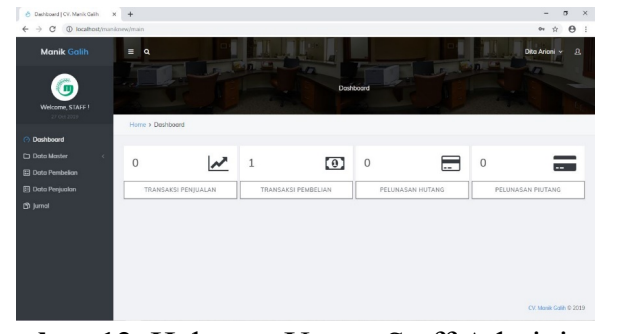

Gambar 12. Halaman Utama Staff Administrasi

\section{Halaman Data Transaksi Pembelian Alat dan Bahan}

Pada Gambar 13 merupakan halaman yang menampilkan data transaksi pembelian alat dan bahan. Selain itu, terdapat aksi tambah data dan search box yang dapat digunakan untuk mengolah data dalam tabel data transaksi pembelian. aksi detail (simbol mata) digunakan hanya untuk menampilkan detail transaksi pembelian, aksi pelunasan (simbol uang) untuk menambah data pelunasan pembelian, dan aksi batal (simbol X) digunakan untuk membatalkan 
transaksi yang dipilih. Menu ini hanya dapat diakses dan dikelola oleh staff administrasi.

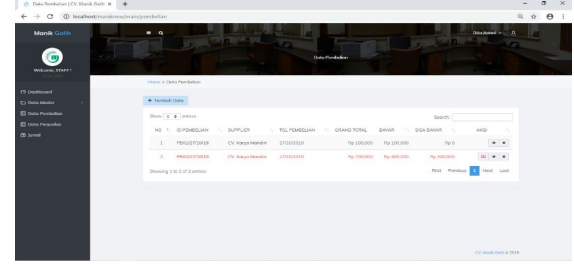

Gambar 13. Halaman Data Pembelian Alat dan Bahan

\section{Halaman Data Transaksi Penjualan Barang Custom}

Pada Gambar 14 merupakan halaman yang menampilkan data transaksi penjualan barang custom. Selain itu, terdapat aksi tambah data dan search box yang dapat digunakan untuk mengolah data dalam tabel data transaksi penjualan. Aksi detail (simbol mata) digunakan hanya untuk menampilkan detail transaksi penjualan, aksi pelunasan (simbol uang) untuk menambah data pelunasan penjualan, dan aksi batal (simbol X) digunakan untuk membatalkan transaksi yang dipilih. Menu ini hanya dapat diakses dan dikelola oleh staff administrasi.

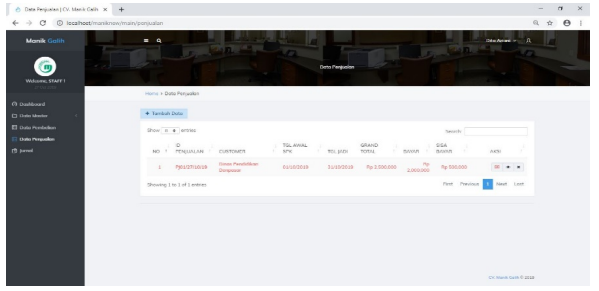

Gambar 14. Halaman Data Penjualan Barang Custom

\section{Halaman Data Jurnal}

Pada Gambar 15, pada halaman data jurnal terdapat tabel yang menampilkan daftar transaksi pada jurnal umum dan jurnal penyesuaian. Selain itu, terdapat aksi tambah data, aksi batal, aksi detail, dan search box yang dapat digunakan untuk mengolah data dalam tabel data jurnal. Aksi detail digunakan hanya untuk menampilkan detail jurnal dan aksi batal digunakan untuk membatalkan data jurnal yang dipilih. Menu ini hanya dapat diakses dan dikelola oleh staff administrasi.

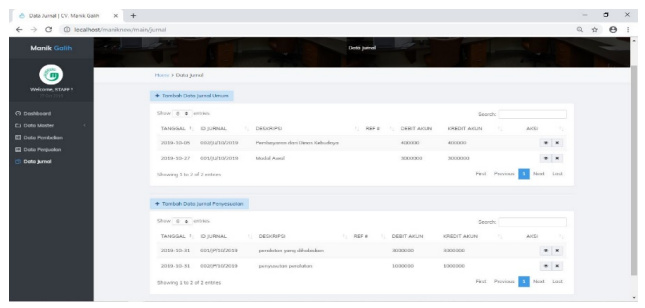

Gambar 15. Halaman Data Jurnal

\section{Halaman Data Laporan}

Pada Gambar 16 yakni halaman data laporan terdapat 8 jenis laporan yang bisa dipilih yakni laporan jurnal umum, laporan daftar pembatalan, laporan jurnal penyesuaian, laporan pembelian, laporan penjualan, laporan laba rugi, laporan buku besar, dan laporan neraca. Untuk melihat detail laporan, maka pemilik dapat menekan aksi laporan sesuai dengan laporan yang dibutuhkan. Kemudian masukkan periode laporan.

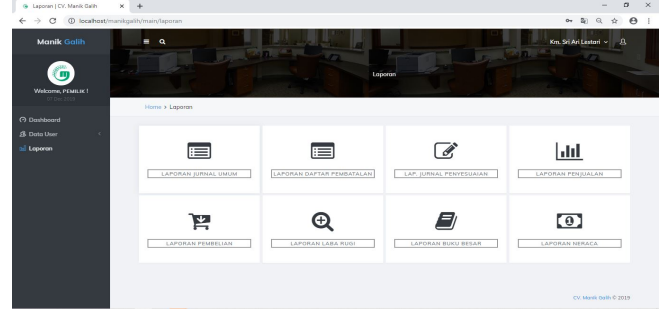

Gambar 16. Halaman Data Laporan

\section{Halaman Laporan Laba Rugi}

Pada laporan laba rugi, pemilik dapat melihat gambaran hasil operasi perusahaan selama periode yang dipilih. Laporan laba rugi dapat dilihat pada Gambar 17.

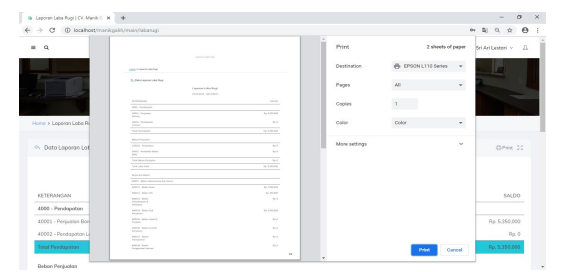

Gambar 17. Halaman Laporan Laba Rugi

\section{Halaman Laporan Buku Besar}

Pada laporan buku besar, pemilik dapat melihat gambaran keuangan perusahaan sesuai dengan akunakun yang digunakan. Laporan buku besar dapat dilihat pada gambar 18 .

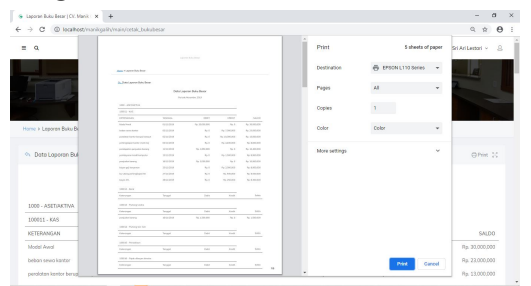

Gambar 18. Halaman Laporan Buku Besar

\section{Halaman Laporan Neraca}

Pada laporan neraca, pemilik dapat melihat gambaran posisi keuangan perusahaan dan keseimbangan antara aktiva, dengan kewajiban dan modal. Laporan neraca dapat dilihat pada Gambar 19. 


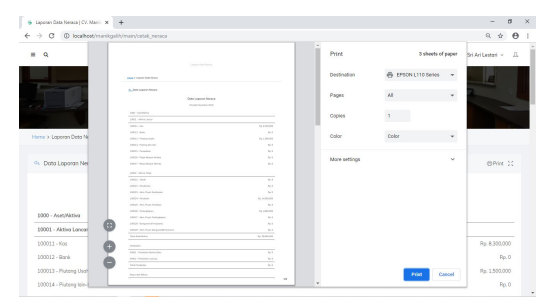

Gambar 19. Halaman Laporan Neraca

\section{KESIMPULAN}

Berdasarkan penelitian yang dilakukan dengan merancang, membangun, menguji, dan menganalisis, dapat disimpulkan sebagai berikut:

1. 'Proses perancangan Sistem Informasi Akuntansi pada CV.Manik Galih ini dimulai dari pengumpulan data yang dibutuhkan dalam pembuatan sistem, kemudian setelah data didapat dan dianalisa kebutuhan sistemnya, selanjutnya merancang alur sistem yang akan dibangun, digambarkan dengan system flow diagram, data flow diagram, conceptual data model, physical data model, dilanjutkan dengan merancang user interface.

2. Proses pembangunan Informasi Akuntansi pada CV.Manik Galih menggunankan bahasa pemrograman PHP dan database MySQL.

3. Dengan dilakukannya pengujian blackbox testing didapatkan hasil bahwa fitur-fitur pada sistem yang dibangun sesuai dengan rancangan dan telah berjalan dengan baik.

\section{DAFTAR PUSTAKA}

David Efendi. (2013). PENGARUH SISTEM

INFORMASI AKUNTANSI DAN KINERJA

KARYAWAN TERHADAP KEEFEKTIFAN

PENGENDALIAN INTERNAL DI

KOPERINDO JATIM CABANG NGANJUK.

Cahaya Aktiva, 03, 72-80.

Diana, A., \& Lilis Setiawati. (2011). Sistem Informasi

Akuntansi, Perancangan, Prosedur dan

Penerapan (2011th ed). Yogyakarta: Andi

Yogyakarta.

Duma Megaria Elisabeth. (2019). KAJIAN

TERHADAP PERANAN TEKNOLOGI

INFORMASI DALAM PERKEMBANGAN

AUDIT KOMPUTERISASI (STUDI KAJIAN

TEORITIS). METHOMIKA: Jurnal Manajemen

Informatika \& Komputerisasi Akuntansi, 3.

Hua, A. K. (2016). Pengenalan Rangkakerja

Metodologi dalam Kajian Penyelidikan : Satu

Kajian Kes. Malaysian Journal of Social

Sciences and Humanities.

https://doi.org/10.6084/M9.FIGSHARE.336265
6

James A Hall. (2011). Sistem Informasi Akuntansi (Edisi 4). Jakarta: Salemba Empat.

Juniastini, N. P. E. J. N. P. E. (2018). SISTEM INFORMASI AKUNTANSI BERBASIS WEB

PADA PT. TAMAN SARI WISATA BAHARI. Denpasar: STMIK STIKOM INDONESIA.

Megawati, \& Putra, I. R. A. (2018). Rancang Bangun Sistem Informasi Akuntansi Berbasis Web ( Studi Kasus Pada PT. Kalber ). Jurnal Sains, Teknologi dan Industri, 15, 98-104.

MH Adzim. (2015). PERANCANGAN SISTEM INFORMASI AKUNTANSI PENGELUARAN KAS BERBASIS KOMPUTER PADA UNIT PRODUKSI SMK NEGERI 6 PALEMBANG. Palembang: Politeknik Negeri Sriwijaya.

Mulyadi. (2016). Sistem Akuntansi (Edisi Keem). Jakarta: Salemba Empat.

Sutarman. (2009). Pengantar Teknologi Informasi. Jakarta: Bumi Aksara.

Suwardjono. (2014). Teori Akuntansi Perekayasaan Pelaporan Keuangan (Edisi keti). Yogyakarta: BPFE Yogyakarta.

Umi Narimawati. (2010). Metodologi Penelitian Kualitatif dan Kuantitatif: Teori dan Aplikasi.

Yulianton, H., Sutanto, F. A., \& Mulyani, S. (2014). Rancang Bangun Sistem Informasi Keuangan Berbasis Area untuk Pengusaha Kecil (Studi Kasus Batik Wijayanti Semarang). Jurnal Teknologi Informasi DINAMIK, 19. 